\title{
ORAL HEALTH BEHAVIOUR AND AWARENESS OF YOUNG POPULATION IN TURKEY
}

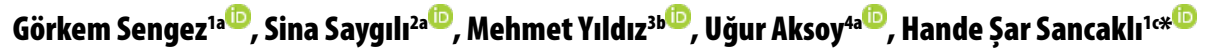 \\ 'Department of Restorative Dentistry, Faculty of Dentistry, Istanbul University, 34093, Çapa-Fatih, Istanbul, Turkey \\ 2Department of Prosthodontics, Faculty of Dentistry, Istanbul University, 34093, Çapa-Fatih, Istanbul, Turkey, \\ ${ }^{3}$ Department of Dental Services, Faculty of Dentistry, Toros University, 33140, Yenişehir, Mersin, Turkey \\ ${ }^{4}$ Department of Endodontics, Faculty of Dentistry, Istanbul University, 34093, Çapa-Fatih, Istanbul, Turkey
}

aDDS, PhD, Researcher

${ }^{b} D D S$

'DDS, PhD, Associate Professor

Introduction: Transition from adolescence to adulthood is an important episode in life since it determines a person's long-time health behavior and their tendency to carry chronic diseases. The present study aims to assess oral health behavior and awareness of the young population in Turkey.

Methodology: A sample of 2,740 students (1309 male, 1431 female) from 5 different universities studying 10 different degree subjects completed a questionnaire related to their oral health behavior. Age, gender and degree subjects were also recorded. The data were analyzed using SPSS 21.0.

Results: $66.6 \%$ of the students brushed their teeth twice or more times daily. The brushing frequency of students studying different degree subjects is significantly different $(p<0.01)$. Dental students have the highest brushing frequency whereas sports students have the lowest. $38 \%$ of the participants indicated that they use mouthwash; however, only $21.2 \%$ used it daily. $21.2 \%$ of the participants visit a dentist once or twice per year. $50.9 \%$ of the participants experience bleeding while brushing. Only $28.8 \%$ had regular scaling and polishing. $22.6 \%$ of the participants smoke, while $18.8 \%$ stated that they have halitosis.

Conclusion: The present study indicated that oral health behavior of young population needs to be further improved. Therefore, oral health education programs should be initiated to emphasize the importance of oral hygiene.

Keywords: Oral hygiene; health attitude; health education; health risk behaviors; toothbrushing.

\section{Introduction}

As one of the world's leading authority on oral health, theWorld Dental Federation (FDI) identifies dental caries and periodontal diseases among the most common and crucial global oral health burdens [1]. Scientific evidence shows a significant relationship between oral health and general health. Non-communicable diseases such as cancer, diabetes, respiratory, cardiovascular and oral diseases share mutual risk factors. The possibility of having systemic diseases increase in the presence of periodontitis, or vice versa $[2,3]$. VanWormer et al. stated that participants with poor oral hygiene have higher cardiovascular disease risk than those who have good oral health [4].

Prevention of oral diseases is the most efficient approach to ensure oral health. The primary etiologic factor of periodontal diseases is microbial plaque; therefore, they can mostly be prevented by plaque control. The most common way to remove plaque is tooth brushing and flossing as they avoid plaque accumulation on teeth and gums. Plaque elimination also contributes to the prevention of caries $[5,6]$. It is known that people who adopted the habit of brushing their teeth at least twice a day have less dental caries compared to others. Apart from the toothbrush, oral hygiene aids such as interdental brush, tongue cleanser, chewing gum and mouthwash can be used in oral healthcare regimen [7].

Consistent health behavior is established at the early stages of human life, with the help of the parents, teachers and caretakers [8,9]. At the age of the transition from childhood to adulthood, a teenager's routines and habits are likely to be challenged since they experience independence for the first time and carry more responsibilities. During their university years students encounter new experiences, stress, social pressure and busyness. Oral and general hygiene habits can become less important with the intrusion of all these factors $[8,10]$.

Through the review of the related literature, there are some studies which observe the oral health behavior of young population around the world. Different findings were reported depending on cultural beliefs, financial situation and education strategies [10-12]. There are 
only a few studies investigated the oral health behavior of Turkish university students. This study aims to determine the oral health habits of university students from five different universities and ten different departments [13-15].

The hypothesis of the present study is that there would be slight differences on the evaluation of oral health awareness level of the current young generation considering their awareness and tendency regarding the oral health care behavior.

\section{Material and Methods}

This study was conducted at five university campuses in different cities of Turkey, which were Gazi University (Ankara), Istanbul University (Istanbul), Abant Izzet Baysal University (Bolu), Ege University (Izmir) and Kocaeli University (Kocaeli). Universities from different cities with a high average student count were selected in order to represent the situation in different areas of Turkey with an adequate number of subjects. The student numbers at the respective campuses were 21270 for Gazi University, 6171 for Istanbul University, 21568 for Abant Izzet Baysal University, 27439 for Ege University and 23951 for Kocaeli University. Participation was voluntary and anonymous.

On World Oral Health Day (March 20 ${ }^{\text {th }}, 2012$ ), desks were set by volunteer dental students in a popular area of the campuses. The volunteers were prepared during a 2 hour-training by a professor from their universities before the event. On the day of the event, the students were invited to participate in the study. They were informed about the study and signed a consent form if they agreed to participate. 3150 students were asked, 2740 agreed to participate. The participation rate was $87 \%$. After completing the survey, the participants were given an oral health education lecture. The study included 2740 undergraduate students (1309 male, 1431 female) enrolled in different faculties which were Sports, Dentistry, Pharmacy, Science, Nursing, Economics, Engineering, Teaching, Humanities and Social Sciences and Medicine.

As reviewed in similar studies, an 11-item questionnaire was designed and validated through a pilot survey before. The questions were designed to evaluate oral health habits and awareness of the students enrolled in different faculties. Age, gender, degree subject were also recorded. Participants were asked to fill out the self-administered questionnaire (Fig. 1). They received an explanation of how to fill in. The questionnaires were collected immediately after they were filled and volunteer dental students gave participants an oral care education lecture.

\subsection{Statistical Analysis}

The data obtained were organized into Microsoft Excel (Microsoft Inc., USA) and analyzed statistically using SPSS 21.0 software (IBM Inc., USA). The standard descriptive methods were applied to determine the characteristics of the sample. Each data set was tested for normality with the Kolmogorov-Smirnov test. Categorical variables between groups were compared by the Pearson's chi-square test. The confidence interval was set to $95 \%$ and $p$-values less than 0.05 were considered statistically significant.

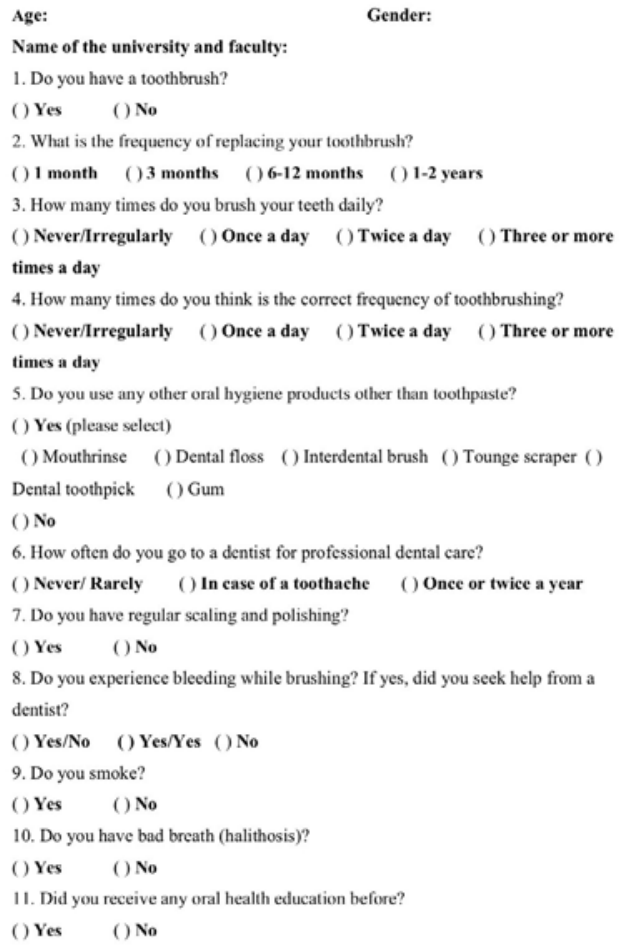

Figure 1. Sample of the questionnaire used in the present study.

I Table 1. Distribution of students by university, gender, age and degree subject.

\begin{tabular}{lccc}
\hline Characteristics & $\mathbf{n}$ & $\%$ & Mean \\
\hline City & & & \\
Ankara & 275 & 10 \\
Istanbul & 574 & 20.9 \\
Bolu & 569 & 20.8 & \\
Izmir & 638 & 23.3 \\
Kocaeli & 684 & 25 & \\
Gender & & \\
Male & 1309 & 47.7 \\
Female & 1431 & 52.3 \\
Age & & \\
Degree Subject & & \\
Sports & 68 & 2.5 \\
Dentistry & 92 & 3.4 \\
Pharmacy & 33 & 1.2 \\
Science & 246 & 9.0 \\
Nursing & 55 & 2.0 \\
Economics & 114 & 4.2 \\
Engineering & 461 & 16.8 \\
Teaching & 536 & 19.6 \\
Social Sciences & 559 & 20.4 \\
Medicine & 576 & 21.0 \\
\hline
\end{tabular}

\section{Results}

The answers of the students according to degree subject were given in Table $2.52,8 \%$ of the participants changed 
I Table 2. Frequency of toothbrushing, use of oral hygiene aids, smoking, receiving oral health education before and belief of the correct frequency of toothbrushing

\begin{tabular}{|c|c|c|c|c|c|c|c|c|c|c|c|c|c|c|}
\hline & \multicolumn{5}{|c|}{ Frequency of Toothbrushing } & \multicolumn{2}{|c|}{ Oral Hygiene Aids } & \multicolumn{2}{|c|}{ Smoking } & \multicolumn{2}{|c|}{ Oral Health Education } & \multicolumn{3}{|c|}{ Belief of the Correct Frequency of TB } \\
\hline & Never & $\begin{array}{c}\text { Once a } \\
\text { day }\end{array}$ & $\begin{array}{c}\text { Twice a } \\
\text { day }\end{array}$ & $\begin{array}{c}\text { Thricea } \\
\text { day/more }\end{array}$ & $\begin{array}{c}\text { After each } \\
\text { meal }\end{array}$ & Yes & No & Yes & No & Yes & No & $\begin{array}{c}\text { Once a } \\
\text { day }\end{array}$ & $\begin{array}{c}\text { Twice a } \\
\text { day }\end{array}$ & $\begin{array}{c}\text { Thrice a } \\
\text { day/more }\end{array}$ \\
\hline Sports & $3(4.4)$ & $28(41.2)$ & $29(42.6)$ & $7(10.3)$ & $1(1.5)$ & $66(97.1)$ & $2(2.9)$ & $23(33.8)$ & $45(66.2)$ & $34(50)$ & $34(50)$ & $4(5.9)$ & $39(57.4)$ & $25(36.8)$ \\
\hline Dentistry & $4(4.3)$ & $16(17.4)$ & $62(67.4)$ & $10(10.9)$ & $0(0)$ & $92(100)$ & $0(0)$ & $25(27.2)$ & $67(72.8)$ & $47(51.1)$ & $45(48.9)$ & $2(2.2)$ & $57(64)$ & $30(33.7)$ \\
\hline Pharmacy & $3(9.1)$ & $7(21.2)$ & $20(60.6)$ & $2(6.1)$ & $1(3)$ & $33(100)$ & $0(0)$ & $9(27.3)$ & $24(72.7)$ & $17(51.5)$ & $16(48.5)$ & $3(9.1)$ & $18(54.5)$ & $12(36.4)$ \\
\hline Science & $7(2.8)$ & $72(29.3)$ & $136(55.3)$ & $27(11)$ & $4(1.6)$ & $241(98)$ & $5(2)$ & $50(20.3)$ & $196(79.7)$ & $135(54.9)$ & $111(45.1)$ & $18(7.4)$ & $113(46.3)$ & $113(46.3)$ \\
\hline Nursing & $1(1.8)$ & $23(41.8)$ & $29(52.7)$ & $1(1.8)$ & $1(1.8)$ & $55(100)$ & $0(0)$ & $11(20)$ & $44(80)$ & $27(49.1)$ & $28(50.9)$ & $6(10.9)$ & $25(45.5)$ & $24(43.6)$ \\
\hline Economics & $10(8.8)$ & $29(25.4)$ & $67(58.8)$ & $8(7)$ & $0(0)$ & $111(97.4)$ & $3(2.6)$ & $23(20.2)$ & $91(79.8)$ & $52(45.6)$ & $62(54.4)$ & $10(8.9)$ & $58(51.8)$ & $44(39.3)$ \\
\hline Engineering & $24(5.2)$ & $136(29.5)$ & $253(54.9)$ & $38(8.2)$ & $10(2.2)$ & $450(97.6)$ & $11(2.4)$ & $117(25.4)$ & $344(74.6)$ & $226(49)$ & $235(51)$ & $33(7.3)$ & $233(51.2)$ & $189(41.5)$ \\
\hline Teaching & $35(6.5)$ & $137(25.6)$ & $322(60.1)$ & $35(6.5)$ & $7(1.3)$ & $508(94.8)$ & $28(5.2) \mathrm{a}$ & $110(20.5)$ & $426(79.5)$ & $250(46.6)$ & $286(53.4)$ & $27(5.1)$ & $255(47.9)$ & $250(47)$ \\
\hline Social Sciences & $29(5.2)$ & $148(26.5)$ & $327(58.5)$ & $50(8.9)$ & $5(0.9)$ & $554(99.1)$ & $5(0.9) b$ & $133(23.8)$ & $426(76.2)$ & $277(49.6)$ & $282(50.4)$ & $31(5.6)$ & $275(49.5)$ & $249(44.9)$ \\
\hline Medicine & $31(5.4)$ & $172(29.9)$ & $327(56.8)$ & $36(6.3)$ & $10(1.7)$ & $555(96.4)$ & 21 (3.6)a & $118(20.5)$ & $458(79.5)$ & $353(61.3)$ & $223(38.7)$ & $30(5.3)$ & $329(57.7)$ & $211(37)$ \\
\hline $\mathbf{p}$ & & & 0.072 & & & 0.0 & & 0. & 162 & & & & 0.025 & \\
\hline
\end{tabular}

their toothbrush every 3 months, while $30,1 \%$ of them changed every $6-12$ months. About $28 \%$ of the students brushed their teeth once, $57.4 \%$ of them twice, $9.2 \%$ of them three times per day. $5.4 \%$ never or irregularly brushed their teeth. There is no significance between faculty and frequency of toothbrushing ( $p>0.05$ ). $54.4 \%$ of sports students, $79.4 \%$ of dentistry, $69.7 \%$ of pharmacy, $67.9 \%$ of science, $65.8 \%$ of economics, $65.3 \%$ of engineering, $67.9 \%$ of teaching, $68.3 \%$ of humanities and social sciences and $64.8 \%$ of medicine students brushed their teeth twice or more times daily.

$97.3 \%$ of the students used one or more oral care product other than toothpaste included mouthwash (38\%), gum (31.8\%), floss (26.5\%), tongue scraper (13.5\%), dental toothpick (6.4\%) and interdental brush (4.7\%). $72.8 \%$ of the participants never/irregularly used mouthwash, while $15.4 \%$ used once and $5.8 \%$ twice a day. There is a statistical significance between oral hygiene aids usage by students from different faculties. Table 3 presents the summary statistics for receiving oral health education (OHE) before.

Dental care visit is in relation with receiving oral health education $(p<0,01)$. Of those whom received $\mathrm{OHE}, 43.1 \%$ never visits a dentist, $33.6 \%$ visits in case of a toothache and $23.3 \%$ visits twice annualy. These percentages are statistically significant.

There is a statistical significance in the frequency of toothbrushing between OHE receivers and nonreceivers. $3.7 \%$ of the $\mathrm{OHE}$ receivers stated they never or irregularly brush their teeth while $7.1 \%$ non-receivers did the same. $60.2 \%$ of the OHE receivers and $54.4 \%$ of non-receivers brush their teeth twice a day. There is no significance in students who brush their teeth three times or more daily.

The students who experience halitosis is higher than students who did not receive OHE than those who received.

$28.8 \%$ of the students had regular scaling and polishing. In Table 4, the relationship between bleeding while tooth brushing and regular scaling/polishing were provided ( $p$ $<0.05)$. $15.8 \%$ of the subjects who had regular scaling (1-2 times/year) experienced bleeding during brushing while $35.2 \%$ of the ones who did not have regular scaling experienced the same problem. Among these students, only $16.8 \%$ sought help from a dentist.

Table 5 presents an overview of smoking habits among students. $77.4 \%$ of the students were nonsmokers and $22.6 \%$ of them were smokers. Brushing frequency among smokers and nonsmokers were statistically
Table 3. Percentages of oral-health education receivers and non-receivers of dentist visits, frequency of toothbrushing and halithosis.

\begin{tabular}{|c|c|c|c|}
\hline \multirow{2}{*}{$\begin{array}{l}\text { Dental Care } \\
\text { Visit }\end{array}$} & \multicolumn{2}{|c|}{ Oral Health Education } & \multirow{2}{*}{$\mathbf{p}$} \\
\hline & Yes & No & \\
\hline $\begin{array}{l}\text { Never/Rarely } \\
(n=1293)\end{array}$ & $\begin{array}{c}611 \\
(43.1 \%)^{*}\end{array}$ & $\begin{array}{c}682 \\
(51.6 \%)\end{array}$ & \multirow{3}{*}{$<0.001$} \\
\hline $\begin{array}{l}\text { In case of a } \\
\text { toothache } \\
(n=866)\end{array}$ & $\begin{array}{c}476 \\
(33.6 \%)^{*}\end{array}$ & $\begin{array}{c}390 \\
(29.5 \%)\end{array}$ & \\
\hline $\begin{array}{l}\text { Twice a year } \\
(n=580)\end{array}$ & $\begin{array}{c}330 \\
(23.3 \%)^{*}\end{array}$ & $\begin{array}{c}250 \\
(18.9 \%)\end{array}$ & \\
\hline \multicolumn{4}{|l|}{$\begin{array}{l}\text { Frequency of } \\
\text { toothbrushing }\end{array}$} \\
\hline $\begin{array}{c}\text { Never/ } \\
\text { Irregularly } \\
(\mathrm{n}=146)\end{array}$ & $\begin{array}{c}52 \\
(3.7 \%)^{*}\end{array}$ & $\begin{array}{c}94 \\
(7.1 \%)\end{array}$ & \multirow{4}{*}{$<0.001$} \\
\hline $\begin{array}{l}\text { Once daily } \\
(n=769)\end{array}$ & $\begin{array}{c}372 \\
(26.2 \%)^{*}\end{array}$ & $\begin{array}{c}397 \\
(30.0 \%)\end{array}$ & \\
\hline $\begin{array}{l}\text { Twice daily } \\
(n=1573)\end{array}$ & $\begin{array}{c}854 \\
(60.2 \%)^{*}\end{array}$ & $\begin{array}{c}719 \\
(54.4 \%)\end{array}$ & \\
\hline $\begin{array}{l}\text { Thrice or more } \\
\text { daily }(n=252)\end{array}$ & $\begin{array}{c}140 \\
(9.9 \%)\end{array}$ & $\begin{array}{c}112 \\
(8.5 \%)\end{array}$ & \\
\hline \multicolumn{4}{|l|}{ Halithosis } \\
\hline Yes $(n=516)$ & $\begin{array}{c}225 \\
(15.9 \%)\end{array}$ & $\begin{array}{c}291 \\
(22.0 \%)\end{array}$ & \multirow{2}{*}{$<0.001$} \\
\hline No $(n=2224)$ & $\begin{array}{c}1193 \\
(84.1 \%)\end{array}$ & $\begin{array}{c}1031 \\
(78.0 \%)\end{array}$ & \\
\hline
\end{tabular}

*Cells which cause signification

Table 4. Frequencies of bleeding during brushing.

\begin{tabular}{|c|c|c|c|c|}
\hline & & \multicolumn{2}{|c|}{$\begin{array}{l}\text { Bleeding during } \\
\text { brushing }\end{array}$} & \multirow[t]{2}{*}{ Total } \\
\hline & & Yes & No & \\
\hline \multirow{2}{*}{$\begin{array}{l}\text { Regular } \\
\text { Scaling \& } \\
\text { Polishing }\end{array}$} & Yes & $15.8 \%$ & $13.0 \%$ & $28.8 \%$ \\
\hline & No & $35.2 \%$ & $36.0 \%$ & $71.2 \%$ \\
\hline \multicolumn{2}{|c|}{ Total } & $51.0 \%$ & $49.0 \%$ & $100.0 \%$ \\
\hline
\end{tabular}

$<0.05$

Table 5. Brushing frequency of smokers and non-smokers.

\begin{tabular}{|c|c|c|c|c|}
\hline & & \multicolumn{2}{|c|}{ Smoking } & \multirow{2}{*}{ Total } \\
\hline & & Yes & No & \\
\hline \multirow{2}{*}{$\begin{array}{l}\text { Frequency of } \\
\text { Toothbrushing }\end{array}$} & $\begin{array}{l}1 \text { or } \\
\text { less }\end{array}$ & $7.2 \%$ & $15.4 \%$ & $22.6 \%$ \\
\hline & $\begin{array}{l}2 \text { or } \\
\text { more }\end{array}$ & $52.8 \%$ & $24.6 \%$ & $77.4 \%$ \\
\hline Total & & $60.0 \%$ & $40.0 \%$ & $100.0 \%$ \\
\hline
\end{tabular}


significant ( $p<0.01$ ). $13.1 \%$ of the smokers never or irregularly brushed, while only $3.1 \%$ of the nonsmokers did the same. In total, $82 \%$ of the non-smokers brushed twice daily, while $68.2 \%$ of the smokers did the same. Sports students evinced the highest smoking rate among students. Dental and pharmacy students followed. Nursing students evinced the lowest rate.

\section{Discussion}

Health behavior is defined as the activities undertaken by people in order to protect, promote or maintain health, and to prevent disease [16]. It can be determined by numbers of factors including education, beliefs, social environment (family, friends, opinion leaders), skills, financial situation and time [17]. Having an excellent oral health care routine which includes tooth brushing, use of dental floss and mouthwash, a balanced diet, frequent (ideally every six months) visits to the dentist will lead to a caries-free oral cavity $[18,19]$. According to previous studies poor dental behavior, diet and smoking are the risk factors of periodontal diseases $[20,21]$. The oral health behavior establishes the health condition of the oral cavity. Chronic oral conditions such as dental caries and periodontitis are common, yet preventable. During a person's lifetime, the progression of these conditions is induced by structural and behavioral factors [22].

Differing among different academic-based students, the hypothesis of the currents study that there would be slight differences on the evaluation of oral health awareness level of the current young generation considering their awareness and tendency regarding the oral health care behavior has been clearly accepted. In the literature review, while some researches evaluated the behavioral aspects of specific groups, no study has evaluated this much of a population in Turkey. The present study reveals that $33.4 \%$ of Turkish university students brush their teeth less than twice a day, which is below the recommended behavior [23]. This data are in accordance with the previous studies which investigates Turkish university students' dental care habits. Peltzer and Pengpid (2014), Kırtıloğlu and Yavuz (2006) and who reported $32 \%$ and $32.4 \%$ of the Turkish students show inadequate brushing respectively $[11,13]$. In the same study of Peltzer and Pengpid, it was also stated that Indian (52.2\%), Lebanese (35\%) and Nigerian $(79.1 \%)$ university students brush their teeth less than twice a day. Previous studies have shown that $92 \%$ of the university students brush their teeth twice or more times a day in Italy [24], and $85 \%$ of the $20-25$ Swedes brush their teeth once or twice a day [25]. 80\% of the university students in the USA are reported to brush their teeth twice or more daily [26]. Other studies conducted in UK and Norway $[27,28]$ have revealed high percentages of brushing twice a day whereas lower findings were reported in Lebanon and Kuwait $[12,29]$. A possible explanation for this discrepancy is that the industrialized and developing countries have significant differences concerning oral health behavior. It could be the reflection of cultural beliefs, education system and financial status $[11,30]$.

As shown in Table 3, the dental students brushing frequency is higher than the other departments, which was an expected outcome. This finding is higher than
Indian (54.4\%) and Iranian (57\%) dental students, but lower than Lithuanian dental students (92\%) [31-33]. In the latter study, $73.3 \%$ of the technology students brushed their teeth twice, which is higher than that of engineering students (65.3\%) in the present study. What is pleasing is that the habits of the students of the teaching department were relatively better than some of the other departments. Taking into consideration that these students will be the future role models for children, this is a good start that needs improvement. In a previous study, it was reported that $90.7 \%$ of the nursing students in Hong Kong brush at least twice a day [34]. Another study revealed that $61 \%$ of the nursing students in Jordan brush at least twice a day [35]. Oral health is known to be closely related to general health. As one of the primary healthcare professionals, nurses are expected to provide a good example to the patients and their community. They also have the task of informing the hospitalized patients or the public of oral health prevention in rural areas, where the number of dentists is relatively low. For this reason, oral health care courses should be given during nursing education [36]. Another critical finding was about the medical students' oral health. The frequency of tooth brushing of medical students is significantly lower than that of dental students. The medical students' frequency of tooth brushing is relatively lower than that of dental students. Medicine education is part of the undergraduate dental curriculum and supported by extensive study of human diseases. However, the involvement of dental subjects in the educational program of medical students is limited [37]. Loster and Likeman (2012) suggested that the basic dental knowledge of medical students will lead to stronger communication between dentists and medical doctors. This suggestion will further support the idea of oral health being a significant part of general health, and professionals of those fields should work together for a healthier community [38].

WHO states that $60-90 \%$ of the schoolchildren and almost $100 \%$ of the adults have dental cavities which indicate an epidemic situation worldwide [39]. Every 92 out of 100 people need treatment for dental caries in Turkey [36]. Visits to a dental professional regularly (once every six months) increase the likelihood of early diagnose of oral diseases [18]. Statistics about the oral health condition and frequency of dentist visits are relatively low in Turkey compared to the global average. $47 \%$ of the population have not visited a dentist in the last year, while $12.5 \%$ have never been to one. $51 \%$ of the patients visit a dentist only when they have a problem and only $\% 10$ visit a dentist for routine dental check-ups [37]. According to the present study results, $19.3 \%$ of the students visit the dentist regularly. The probable cause of this difference is that the oral health knowledge by the young population may be higher than by the general population in Turkey. This can be explained by the effect of college education and higher use of social media among the young population [40]. In reviewing the literature, it was found that $60 \%$ of the Korean dental hygiene students postpone visiting a dentist until they have a toothache, whereas only $1 \%$ of the US dental hygiene students agreed to this remark [36]. In another study, it was found that $41 \%$ of Japanese and only $3 \%$ of Finnish dental students have the same opinion [30]. A study including multiple 
countries found that $58.2 \%$ of university students rarely or never had gone for a dentist visit [11], which is higher than the present study (47.2\%). These results corroborate with the findings of Kawamura et al. (2002) who stated that the Asian way of dealing with the disease is different from the Western concepts and that they only seek professional help when home remedies are unsuccessful [36]. Also, there are other studies conducted in Arab countries like Saudi Arabia and Jordan in which the subjects tend to visit the dentist only if they have a problem or are in pain $[41,42]$. The thought of preventive care being unnecessary and financial status were the major obstacles preventing the subjects from visiting the dental office regularly.

Oral hygiene aids such as mouth rinse, floss and interdental brush should be used as complementary to tooth brushing in order to maintain a better plaque removal from interdental areas [18]. In the present study mouth rinse (38\%) and floss (26.5\%) are the most frequently used aids, while interdental brush $(4.7 \%)$ is the least common oral hygiene aids that the subjects have at home. However, only $21.2 \%$ of them use mouth rinse regularly. These results reflect those of Kırtıloğlu and Yavuz (2006) who also examined the frequency of regular use of antibacterial rinse (18.8\%) and interdental brush (1.6\%) in Turkish students [13]. Cultural belief has a strong relationship with oral hygiene habits. In a study conducted in Saudi Arabia, the use of miswak was found to be high among school children [43]. In a previous study, it was mentioned that $52 \%$ of the students use a toothpick daily, which is a low-cost interdental cleaning device used frequently in Turkey. However, the findings of the current study (6.4\%) do not support previous research. A possible explanation for this might be that the word 'dental toothpick' was used in the questionnaire which may confuse the subjects and prevent them from marking the option even if they use it.

Several reports have shown that $81 \%$ of the Turkish children did not have a regular tooth brushing habit. $72 \%$ of Turkish high school children needed oral health education [14]. The main objective of oral health education is to enhance knowledge which may lead to better oral health behavior [44]. According to the present study results $51.8 \%$ of the subjects had received oral health education. This is lower than another study made in Turkey (61\%) and higher than Lithuanian technology students [13,33]. Oral health education and preventive programs are vital in decreasing caries and periodontal diseases prevalence in children and the young population [13]. Studies have shown that teachers, family and peers have a more significant role than dentists in adopting oral health behavior in adolescents [15]. Oral health education given at school considered to be efficient since the school children are approached at an age when their habits are forming. Besides, such education may not only reach the children but their family and community members [45]. It was shown in a study by Eden et al. (2018) that correct brushing techniques education is more effective if given by teachers than dentists [46]. In the present study, only less than half of the teaching students (46.6\%) had received oral health education. It is important to emphasize more educating future teachers on oral health for a healthier community.
Another finding was that $22.6 \%$ of the university students are smokers and $82 \%$ of the non-smokers brush twice daily, while $68.2 \%$ of the smokers do the same. This finding indicates that poor oral health behavior (smoking) and the frequency of tooth brushing are associated, which is mostly consistent with the previous study findings $[11,12,31]$. Based on these findings, it is suggested that oral and general health promotion programs should be combined and encourage positive health behavior in public [11]. Healthcare professionals have an essential role in smoking cessation $[47,48]$. However, in a study investigating the dentists' role in tobacco control it was suggested that $60 \%$ of the dentists do not routinely recommend the smokers to quit. Therefore, the education of dental students may emphasize more tobacco control of patients [49]. According to present study, Turkish dental and medical students' smoking rates are higher than Lithuanian dental students (12\%) and American medical students $(6.1 \%)$ but lower than that of Italian medical students (29.5\%) [33,50]. Previous studies indicated that non-smoking physicians are more successful at getting patients to quit smoking. Since healthcare professionals have a high impact on patients to establish positive health behavior, future interventions should aim to eliminate tobacco usage among the students [50].

Limitations of this study were the lack of socioeconomic status and background information of the participants. Another limitation is that dental health behavior was only assessed by self-report. This could lead to an optimistic view of the current situation since sometimes respondents tend to overestimate their actual health behaviors due to the social acceptability of their answers. Future studies may include a dental examination and socio-economic status related questions.

\section{Conclusion}

The findings of this study indicated that young Turkish generation sectioned from different parts of the country revealed low level of oral health awareness and behavioral routines; moreover, the overall aspect was found to be of a lesser extent when compared to high-income countries.

Regarding the data indicated there is an association between previous OHE and oral health behavior on which academic tendency plays a differentiating role in oral health behavior. Beside the primary oral health indicators, the risk factors threatening the oral health also needs to be enrolled on the awareness raising programmes. Thus, positive inclined health behavior adopted in the early adult phase of one's life would encourage the young population to adopt better health behavior.

\section{Author Contributions}

GS: planned and organized the study. wrote the manuscript. SS: collected and imported the data into the computer. MY: coordinated the volunteer students in different cities. UA: interpreted the data. HS: provided the critical revision and guidance. 


\section{Acknowledgement}

The authors would like to thank volunteer dental students in five different cities who have worked on the day of the study to distribute the questionnaires and give oral hygiene instructions to the participants.

\section{References}

1. FDI World Dental Federation. FDI policy statement on oral infection/inflammation as a risk factor for systemic diseases: Adopted by the FDI General Assembly: 30 August 2013-Istanbul, Turkey. Int Dent J. 2013;63(6):289-290. [CrossRef] [PubMed] Google Scholar(2)

2. Dörfer C, Benz C, Aida J, Campard G. The relationship of ora health with general health and NCDs: a brief review. Int Dent J. 2017;67 Suppl 2:14-18

[Full text links] [Free PMC Article] [PubMed] Google Scholar(7) Scopus(4)

3. Kanjirath PP, Kim SE, Inglehart MR. Diabetes and oral health: the importance of oral health-related behaviour. J Dent Hyg. 2011:85(4):264-272.

[PubMed] Google Scholar(28) Scopus(15)

4. VanWormer JJ, Acharya A, Greenlee RT, Nieto FJ. Oral hygiene and cardiometabolic disease risk in the survey of the health of Wisconsin. Community Dent Oral Epidemiol. 2013;41(4):374 384.

[Full text links] [PubMed] Google Scholar(7) Scopus(5)

5. Choo A, Delac DM, Messer LB. Oral hygiene measures and promotion: review and considerations. Aust Dent $J$ 2001:46(3):166-173.

[Full text links] [PubMed] Google Scholar(130) Scopus(52)

6. Marsh PD. Microbiology of dental plaque biofilms and their role in oral health and caries. Dent Clin North Am. 2010;54(3):441-454.

[Full text links] [Pubmed] Google Scholar(205) Scopus(61)

7. Gibson S, Williams S. Dental caries in pre-school children: associations with social class, toothbrushing habit and consumption of sugars and sugar-containing foods. Caries Res. 1999;33(2):101-113.

[Full text links] [PubMed] Google Scholar(355) Scopus(142)

8. Small M, Bailey-Davis L, Morgan N, Maggs J. Changes in eating and physical activity behaviours across seven semesters of college: living on or off campus matters. Health Educ Behav. 2013:40(4):435-441.

[Full text links] [PubMed] Google Scholar(141) Scopus(50)

9. Okada M, Kawamura M, Kaihara Y, et al. Influence of parents oral health behavior on oral health status of their school children: an exploratory study employing a causal modelling technique. Int J Paediatr Dent. 2002;12(2):101-108. [Full text links] [PubMed] Google Scholar(194) Scopus(46)

10. Crabtree R, Kirk A, Moore M, Abraham S. Oral health behaviors and perceptions among college students. Health Care Manag (Frederick). 2016;35(4):350-360.

[Full text links] [PubMed] Google Scholar(3) Scopus(46)

11. Peltzer K, Pengpid S. Oral health behavior and social and health factors in university students from 26 low, middle and high income countries. Int J Environ Res Public Health. 2014;11(12):12247-12260.

[Full text links] [PubMed] Google Scholar(7) Scopus(11)

12. Kassak KM, Dagher R, Doughan B. Oral hygiene and lifestyle correlates among new undergraduate university students in Lebanon. J Am Coll Health. 2001:50(1):15-20. [PubMed] Google Scholar(64) Scopus(18)

13. Kırtıloğlu T, Yavuz ÜS. An assessment of oral self-care in the student population of a Turkish university. Public Health. 2006;120(10):953-957.

[Full text links] [PubMed] Google Scholar(45) Scopus

14. Kulak-Özkan Y, Ozkan Y, Kazazoglu E, Arikan A. Denta caries prevalence, tooth brushing and periodontal status in 150 young people in Istanbul: a pilot study. Int Dent $J$. 2001:51(6):451-456

[Full text links] [PubMed] Google Scholar(50) Scopus(15)

15. Karadaş M, Tahan E, Köse O, Demirbuğa S. Evaluation of the frequency of tooth brushing in the 13-20 age group of Individuals and the relationship between oral hygiene and DMFT [Article in Turkish]. Turkiye Klinikleri J Dental Sci. 2014;20(3):177-181. Google Scholar(0)

16. Steptoe A, Wardle J, Vinck J, et al. Personality and attitudina correlates of healthy and unhealthy lifestyles in young adults. Psychol Health. 1994;9(5):331-343. [PubMed] Google Scholar(162) Scopus(71)

17. Park K. Park's textbook of preventive and social medicine. 18 ed. Jabalpur (M.P.), India: M/s. Banarsidas Bhanot; 2005. Google Scholar(2311)
18. Harris NO, Garcia-Godoy F. Primary preventive dentistry. 6th ed. Upper Saddle River (NJ), USA: Pearson Prentice Hall; 2004. 399-409.

Google Scholar(3)

19. Polk DE, Weyant RJ, Manz MC. Socioeconomic factors in adolescents' oral health: are they mediated by oral hygiene behaviors or preventive interventions? Community Dent Oral Epidemiol. 2010;38(1):1-9.

[Full text links] [PubMed] Google Scholar(96) Scopus(44)

20. Amarasena N, Ekanayaka AN, Herath L, Miyazaki H. Tobacco use and oral hygiene as risk indicators for periodontitis. Community Dent Oral Epidemiol. 2002;30(2):115-123. [Full text links] [PubMed] Google Scholar(127) Scopus(67)

21. Pihlstrom BL, Michalowicz BS, Johnson NW. Periodontal diseases. Lancet. 2005; 366(9499):1809-1820.

Google Scholar(2768) Scopus(1680)

22. Fisher-Owens SA, Gansky SA, Platt LJ, et al. Influences on children's oral health: a conceptual model. Pediatrics. 2007;120(3):e510-e520.

[Full text links] [PubMed] Google Scholar(443) Scopus

23. Davies RM, Davies GM, Ellwood RP, Kay EJ. Prevention. Part 4: Toothbrushing: what advice should be given to patients? $\mathrm{Br}$ Dent J. 2003;195(3):135-141. [Full text links] [PubMed] Google Scholar(7) Scopus

24. Rimondini L, Zolfanelli B, Bernardi F, Bez C. Self-preventive oral behavior in an Italian university student population. $J$ Clin Periodontol. 2001;28(3):207-211.

[Full text links] [PubMed] Google Scholar(109) Scopus

25. Stenberg $\mathrm{P}$, Håkansson J, Ákerman S. Attitudes to dental health and care among 20 to 25 -year-old Swedes: results from a questionnaire. Acta Odontol Scand. 2000;58(3):102106.

[Full text links] [PubMed] Google Scholar(67) Scopus(22)

26. Luebke TE, Driskell JA. A group of Midwestern university students needs to improve their oral hygiene and sugar/pop consumption habits. Nutr Res. 2010;30(1):27-31.

[Full text links] [PubMed] Google Scholar(12) Scopus(3)

27. Bradnock G, White DA, Nuttall NM, et al. Dental attitudes and behaviors in 1998 and implications for the future. Br Dent J. 2001;190(5):228-232.

[PubMed] Google Scholar(56) Scopus

28. Åstrøm AN, Samdal O. Time trends in oral health behaviors among Norwegian adolescents: 1985-97. Acta Odontol Scand. 2001;59(4):193-200.

[PubMed] Google Scholar(37) Scopus

29. Al-Ansari J, Honkala E, Honkala S. Oral health knowledge and behavior among male health sciences college students in Kuwait. BMC Oral Health. 2003:3(1):2.

[Full text links] [PubMed] Google Scholar(64) Scopus(35)

30. Kawamura M, Honkala E, Widström E, Komabayashi T. Cross-cultural differences of self-reported oral health behavior in Japanese and Finnish dental students. Int Dent J. 2000;50(1):46-50.

[Full text links] [PubMed] Google Scholar(121) Scopus(41)

31. Sharda AJ, Shetty S. A comparative study of oral health knowledge, attitude and behaviour of first and final year dental students of Udaipur city, Rajasthan, India. Int J Dent Hyg. 2008;6(4):347-353.

[Full text links] [PubMed] Google Scholar(72) Scopus(18)

32. Khami MR, Virtanen Jl, Jafarian M, Murtomaa H. Oral health behavior and its determinants amongst Iranian dental students. Eur J Dent Educ. 2007:11(1):42-47.

[Full text links] [PubMed] Google Scholar(81) Scopus

33. Pacauskiene IM, Smailiene D, Siudikienè J, et al. Self-reported oral health behavior and attitudes of dental and technology students in Lithuania. Stomatologija. 2014;16(2):65-71. [Full text links] [PubMed] Google Scholar(18) Scopus(5)

34. Chan JC, Chin LS. Oral health knowledge and psychological determinants of oral health behavior of nursing students. $J$ Health Psychol. 2017;22(1):79-88. [Full text links] [PubMed] Google Scholar(6) Scopus(2)

35. Alsrour SS, Nassrawin N, Al-Tawarah YM. Oral health knowledge, attitudes and behavior of nursing students at Mutah University (Jordan). Pakistan Oral Dent $J$. 2013;33(1):102-109. Google Scholar(8)

36. Kawamura M, Spadafora A, Kim KJ, Komabayashi T. Comparison of United States and Korean dental hygiene students using the Hiroshima university-dental behavioral inventory (HU-DBI). Int Dent J. 2002;52(3):156-162. [Full text links] [PubMed] Google Scholar(78) Scopus(28)

37. Kılınç G, Günay T. The knowledge level of the last year students of Dokuz Eylül University Faculty of Medicine about oral health. [Article in Turkish]. Dokuz Eylül Üniversitesi Tıp Fakültesi Dergisi. 2010;24(3):131-137. Google Scholar(10)

38. Loster BW, Likeman PR. Teaching of dentistry to medical students in English at the Jagiellonian University, Krakow, Poland. Eur J Dent Educ. 2012;16(1):1-2. [Full text links] [PubMed] Google Scholar(5) Scopus 
39. WHO - World Health Organization. Oral Health. Fact sheet no. 318, April. 2012. Available from www who.int/mediacentre/ factsheets/fs318/en/index.htm. Accessed on 17 January 2015

40. Gholami M, Pakdaman A, Montazeri A, et al. Assessment of periodontal knowledge following a mass media oral health promotion campaign: a population-based study. BMC Oral Health. 2014;14(31):1-7

[Full text links] [PubMed] Google Scholar(22) Scopus(11)

41. Quteish Taani DQ. Dental fear among young adult Saudian population. Int Dent J. 2001;51(2):62-66.

[Full text links] [PubMed] Google Scholar(74) Scopus

42. Taani DQ. Periodontal awareness and knowledge, and pattern of dental attendance among adults in Jordan. Int Dent J. 2002;52(2):94-98.

[Full text links] [PubMed] Google Scholar(91) Scopus(27)

43. Farsi JM, Farghaly MM, Farsi N. Oral health knowledge, attitude and behavior among Saudi school students in Jeddah city. J Dent. 2004;32(1):47-53.

[Full text links] [PubMed] Google Scholar(116) Scopus(38)

44. Nakre PD, Harikiran AG. Effectiveness of oral health education programs: a systematic review. J Int Soc Prev Community Dent. 2013;3(2):103-115.

[Full text links] [PubMed] Google Scholar(67)

45. Mota A, Oswal KC, Sajnani DA, Sajnani AK. Oral health knowledge, attitude, and approaches of pre-primary and primary school teachers in Mumbai, India. Scientifica (Cairo). 2016;2016:5967427.

[Full text links] [PubMed] Google Scholar(12) Scopus(1)
46. Eden E, Akyildiz M, Sönmez I. Comparison of two schoolbased oral health education programs in 9-year-old children. Int Q Community Health Educ. 2019;39(3):189-196. Google Scholar(3) Scopus

47. Stead LF, Buitrago D, Preciado N, et al. Physician advice for smoking cessation. Cochrane Database Syst Rev. 2013;(5):CD000165

[Full text links] [PubMed] Google Scholar(1305) Scopus(350)

48. Lim G, Park I, Park S, et al. Effectiveness of smoking cessation using motivational interviewing in patients consulting a pulmonologist. Tuberc Respir Dis (Seoul). 2014;76(6):276-283. [Full text links] [PubMed] Google Scholar(11) Scopus(4)

49. Tomar SL. Dentistry's role in tobacco control. J Am Dent Assoc 2001;132 Suppl:30S-35S.

[Full text links] [PubMed] Google Scholar(194) Scopus(96)

50. Armstrong GW, Veronese G, George PF, et al. Assessment of tobacco habits, attitudes, and education among medical students in the United States and Italy: a cross-sectional survey. J Prev Med Public Health. 2017;50(3):177-187. [Full text links] [PubMed] Google Scholar(5) Scopus(3)

\section{Görkem SENGEZ \\ DDS, PhD, Researcher Department of Restorative Dentist, Faculty of Dentistry Istanbul University Istanbul, Turkey}

Görkem Sengez, DDS, received her degree in dentistry in 2014 from the Istanbul University. Dr. Sengez is currently a PhD at the Department of Restorative Dentistry, Istanbul University, Istanbul, Turkey. She is a young researcher whose area of interest includes esthetic dentistry, shade matching and laminate veneers.

\section{Orestions}

\section{Which one is an important factor in developing health behaviors?}
a. Family;
b. Friends;
口c. Education;
ad. All.

\section{What is the most efficient approach to ensure oral health?}

$\square$ a. Toothbrushing twice a week;

b. Consuming sugary beverages;

ac. Removing microbial plaque regularly;

d. Smoking once a day.

\section{According to the results of this study, which students brush more frequently?}

$\square$ a. Medicine;

b. Dental

ac. Sports;

ad. Science.

\section{Which one is among the most common chronic diseases globally?}

a. Sjögren Syndrome;

b. Dental caries;

ac. Tonge cancer;

d. Behcet's Disease. 